\title{
LUMPY INVESTMENT IN REGULATED NATURAL GAS PIPELINES: AN APPLICATION OF THE THEORY OF THE SECOND BEST
}

\author{
Dagobert L. Brito \\ Department of Economics and Baker Institute, Rice University, and Centro de \\ Investigación y Docencia Económicas (CIDE). Address: [MS-22], 6100 Main Houston, \\ TX 77005; email:brito@ rice.edu \\ Juan Rosellón \\ Centro de Investigación y Docencia Económicas (CIDE)and Technische Universität \\ Dresden (TU Dresden). Address: Carretera México-Toluca no. 3655, Mexico, D.F., \\ 01210, Mexico; email juan.rosellon@ cide.edu
}

\begin{abstract}
We address investment in regulated natural gas pipelines when investment is lumpy and the demand for gas is stochastic. This is a problem that can be solved in theory as a dynamic program, but a practical solution depends on functions and parameters that are either subjective or cannot be estimated. We then reformulate the problem from the standpoint of consumers that face incomplete markets. It is shown that for reasonable parameter values consumers prefer to pay for excess capacity rather than bear the risk of congestion. These strategies can be implemented with reasonably straightforward policies. Since the demand for gas is very inelastic, the welfare losses associated from small deviations from a first best optimum are minimal. This implies that the gas pipeline system can be regulated with a relatively simple set of transparent rules without any significant loss of welfare.
\end{abstract}




\section{Introduction}

The timing of lumpy investment with stochastic demand for pipelines is not a solved problem. It is not a problem that is conceptually difficult, but the information needed is not available. The technology of gas pipelines requires lumpy investment. Once the pressure limits on a pipeline are reached, the only way to add capacity is to add pipe or add pumping stations to increase throughput. The market is not a good guide to the allocation of resources in pipeline capacity. It can take as long as three years lead time to increase pipeline capacity, so it is necessary to rely on forecasts of future demands for the purpose of planning investment in pipeline capacity. These forecasts are at best uncertain. Some of the stochastic elements are short term such as weather and others, such as the price of gas, are long term and can reflect macroeconomic conditions. Such forecasts either do not exist or they are subject to such errors that they are not very useful.

The problem of investing in pipelines with lumpy investment is one that has not been solved. In theory, the problem can be formulated as a dynamic program, but the solution depends on functions and parameters that are either subjective or cannot be estimated. Further, computing a first-best efficient solution may not very useful. The elasticity of the demand for gas is such that small amounts of congestion can cause large fluctuations in price. Inasmuch as many consumers do not have access to complete markets, these fluctuations result in substantial transfers.

In this paper, we formulate the problem in a manner that consumers can choose between an increase in cost of transporting gas against the reduced risk of transfers due to congestion of the pipeline. These investment strategies are not optimal in the strict sense of the word. There is a well-known result in the network literature that an optimal 
investment policy involves some periods where the constraint is binding. However, in a second best world, consumers, who ultimately pay the full cost, may prefer to bear the cost of excess capacity rather than the risk of transfers created by binding constraints. These investment policies are C-efficient if the consumers of the gas bear the cost of moving the gas in the pipeline. ${ }^{1}$

Another issue in the regulation of gas pipelines is the rate structure. The technology of pipelines is such that marginal cost pricing will not cover average costs during a substantial part of the investment cycle. A theoretical solution to the non-lumpy version of this problem is a two-part tariff. However, investment in gas pipelines is lumpy by nature. Since the demand for gas is very inelastic, the welfare losses associated with average cost pricing are small. In particular, this implies that a gas pipeline system could be regulated with a reasonably simple set of rules that regulate investment and rates without any significant loss of welfare. The resulting system can be transparent and a good candidate for some institutional arrangement in which there is substantial

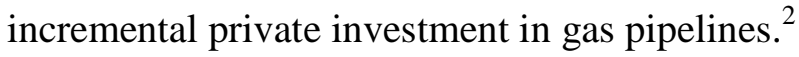

\section{Two-Part Tariff Regulation}

A network transmission firm (Transco) might be regulated to provide it with long-term investment incentives to reach steady state equilibrium where the marginal cost of expansion equals the marginal revenue from congestion. Some mechanisms suggest

\footnotetext{
1 Dierker, Dierker and Grodal (2001) have introduced the concept of S-efficiency in the general equilibrium literature. An allocation is S-efficient if it is optimal for the shareholders of a firm. We define an allocation to be $\mathrm{C}$-efficient for a pipeline if the consumers of gas prefer it to the efficient first-best allocation.

2 Mexico is an example of a gas industry that is owned by a public firm (Pemex) and that has not been successful enough to develop, partly due to the ownership structure but also due to its regulatory framework (see Brito and Rosellón, 2002a, b, 2005a,b; Brito, Littlejohn and Rosellón, 2000; and Rosellón and Halpern, 2001).
} 
comparing the Transco performance with a measure of welfare loss (Léautier, 2000,

Grande and Wangesteen, 2000, and Joskow and Tirole, 2002).

Another trend in the literature is the use of price regulation to provide proper expansion incentives for non-lumpy transmission expansion projects. Vogelsang (2001) has shown that regulation of the price structure can be used to resolve congestion problems of transmission lines in the short run as well as capital costs and investment issues in the long run. Vogelsang proposes a two-part tariff regulatory model with variable (or usage) charges and fixed (or capacity) charges. The Transco is a profitmaximizing monopolist that makes investment and pricing decisions subject to regulation on its two-part tariff. The solution to this problem also takes care of congestion problems by means of the variable charges. Long-term capital costs are recuperated through the fixed charge. Incentives for investment in network expansion are achieved through the rebalancing of the fixed part and the variable part of the tariff. Transmitted volumes for each type of service are used as weights ${ }^{3}$ for the corresponding various prices so that the

3 There are two basic ways to regulate price structure: one with fixed weights --tariff-basket regulation-and another with variable weights --average revenue regulation--. Under the former regime, a maximum limit is established over and index $I(p)=\sum_{i=1}^{n} w_{i} p_{i}$ where $p_{i}$ are the different prices and $w_{i}$ are the fixed weights. Weights might be output (or throughput) quantities of the previous period (chained Laspeyres), quantities of the current period (Paasche), intertemporally fixed quantities (fixed Laspeyres), or projected quantities that correspond to the steady state equilibrium (ideal Laffont-Tirole weights, as in Laffont and Tirole, 1996). Non-fixed variable weights are usually associated to average revenue regulation which sets a cap on incomes per unit but that does not set fixed weights that limit the relative variation of prices. Compared to tariff-basket regulation, this confers the firm greater flexibility in tariff rebalancing. The literature has proved that, under stability conditions of costs and demand -and myopic profit maximization-, the use of the chained Laspeyres index makes the prices of the regulated firm intertemporally converge to Ramsey pricing (Vogelsang 2001, Vogelsang 1989, Bertoletti y Poletti, 1997, Loeb and Magat 1979, and Sibley, 1989). The chained-Laspeyres structure simultaneously reconciles two opposing objectives: the maximization of social welfare and the individual rationality of the firm. Social surplus is redistributed to the monopoly in such a way that long-run fixed costs are recovered but, simultaneously, consumer surplus is maximized over time. Under changing conditions of the cost and demand functions -or under discounted myopic profit maximization - however, a profit maximizing firm subject to a chained Laspeyres constraint might establish prices that diverge from the Ramsey structure (Neu, 1993, Fraser, 1995, Law, 1995, and Brennan, 1989). 
Transco's profits grow as capacity utilization and network expansion increase. In equilibrium, the rebalancing of fixed and variable charges depends on the ratio between the output weight and the number of consumers.

An application of the Vogelsang mechanism to the expansion of natural-gas distribution networks is carried out by Ramírez and Rosellón (2002). Price regulation of natural-gas distribution tariffs in Mexico uses the average-revenue methodology during the first five years of the projects. Tariff-basket regulation is used afterwards. The reason being that the Mexican distribution projects are mainly greenfield meaning that they are characterized in their initial stages by high growth rates -and low participation in total sales_ - of the residential service and, more importantly, by volatile cost and demand conditions. Therefore, average-revenue regulation is more consistent with investment attraction under uncertainty since it is a laxer constraint for firms than the chainedLaspeyres regulation. Ramírez and Rosellón address the effects of this system on consumer surplus. They show that the regime implies incentives for setting two-part tariffs strategically where the variable charge is typically dropped to its lowest feasible level while the fixed charge is raised to compensate for the loss of profit. A stochastic effect is also created due to the endogenous determination of weights that, when combined with competition for the distribution market, implies increased values of consumer surplus for higher levels of risk aversion and uncertainty.

\section{Average Cost Pricing for Gas Pipelines}




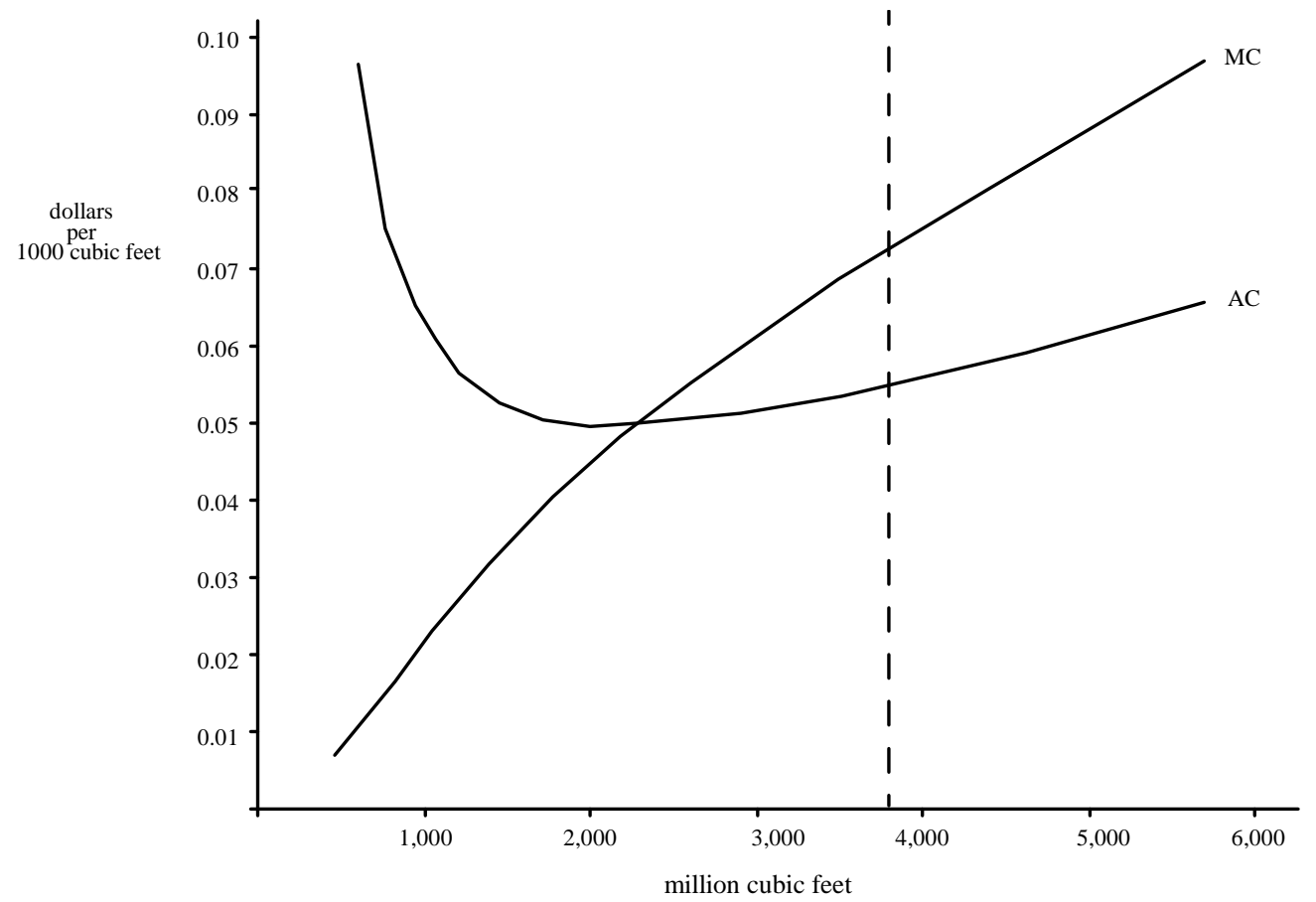

Figure 1

Pipelines have a high fixed cost, and for a substantial portion of their operating region low marginal costs. The capacity of the pipeline is ultimately limited by the pressure limits of pipe. Figure 1 illustrates the cost curves for a 48-inch pipeline 100 miles long. At a pressure limit of 1,500 pounds per square inch, the pipeline reached its limit at approximately 3,800 million cubic feet per day. The dashed line denotes this limit. At this point it becomes impossible to increase throughput by increasing power and it becomes necessary to add compressor stations that increases throughput without exceeding the line limit by increasing the pressure gradient.

In a regulated regime for a gas network, marginal cost pricing results in a loss of rents. One solution to this problem is to set a fee that yields a regulated rate of return over the life of the project sufficient to cover all costs. As discussed in section 2, a more sophisticated alternative is a two-part tariff with a price cap. The sophisticated price cap mechanism is efficient in that it sets the marginal cost of transporting gas equal to the 
variable change for moving gas. The question is whether the more efficient allocation of resources merits the additional difficulties in regulation. The literature described in section 2 of this paper addresses the expansion of non-lumpy networks. Joskow and Tirole (2005) show that lumpiness in transmission investment makes the total value paid to investors less than the social value created. A two-part tariff regulatory system for lumpy transmission projects is thus an unsolved issue in the regulatory-economics literature. In this section we will show that the welfare loss associated with using a simpler average cost rate structure is small, and can probably be ignored.

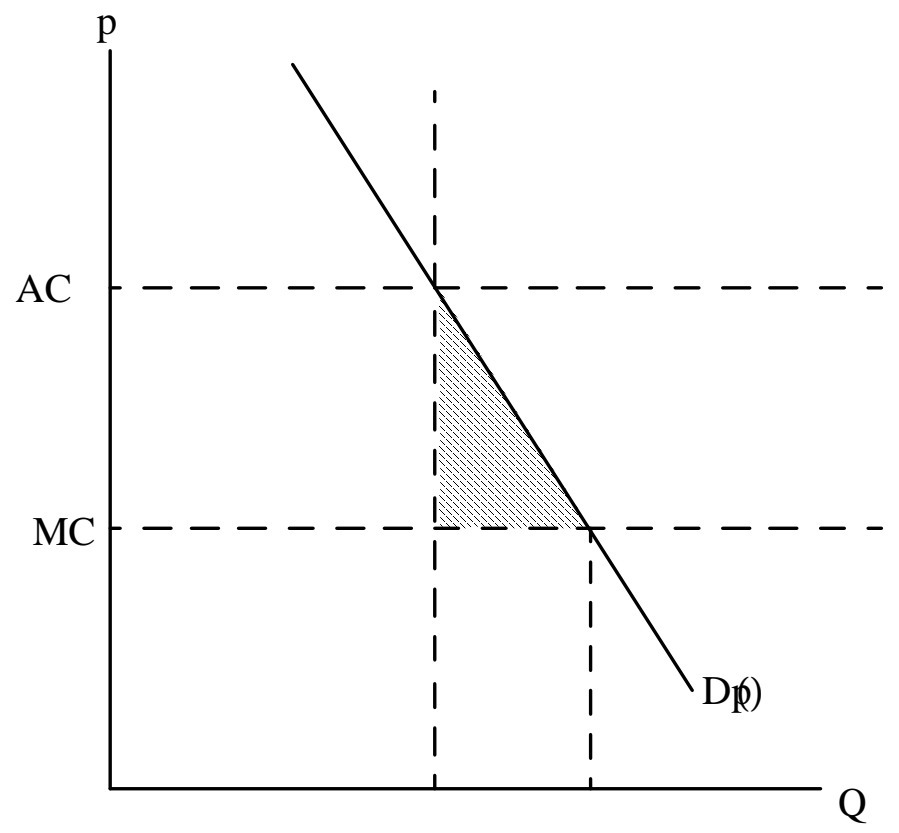

Figure 2

The shaded area in Figure 2 illustrates the welfare loss associated with using average cost rather than marginal cost in transporting gas. The loss, $L$, is given by

$$
L=\frac{(A C-M C)^{2} Q \eta}{2 p}
$$


where $\eta$ is the elasticity of the demand for gas. Simple calculations suggest that for elasticities of the demand for gas in the range of - 0.1 to -0.2 the welfare loss is minimal. We can calculate the dead weight loss associated with using a rate of return fee structure for 4 million thousand cubic feet (MCF) of gas when the price of gas equals $\$ 6.00$ per $\mathrm{MCF}$, the elasticity for the demand for gas is equal to -0.1. If we calculate the change in demand and welfare loss for differentials between $\mathrm{AC}$ and $\mathrm{MC}$ of $\$ 0.10$ to $\$ 0.20$, we get

\begin{tabular}{|c|c|c|}
\hline AC-MC & $\begin{array}{c}\text { Change in } \\
\text { Demand } \\
\text { MCF }\end{array}$ & $\begin{array}{c}\text { Welfare Loss } \\
\text { for 4,000,000 } \\
\text { MCF }\end{array}$ \\
\hline 0.10 & 6,667 & 333.33 \\
\hline 0.11 & 7,333 & 403.33 \\
\hline 0.12 & 8,000 & 480.00 \\
\hline 0.13 & 8,667 & 563.33 \\
\hline 0.14 & 9,333 & 653.33 \\
\hline 0.15 & 10,000 & 750.00 \\
\hline 0.16 & 10,667 & 853.33 \\
\hline 0.17 & 11,333 & 963.33 \\
\hline 0.18 & 12,000 & 1080.00 \\
\hline 0.19 & 12,667 & 1203.33 \\
\hline 0.20 & 13,333 & 1333.33 \\
\hline
\end{tabular}

Table 1

If the difference is $\$ 0.10$, we get that the change in demand is $6,667 \mathrm{MCF}$ and the deadweight loss is $\$ 330$. The welfare loss is quadratic with respect to the differential, the deadweight loss is $\$ 1,333$ if the differential is $\$ .20$. This is on the order of .0003 cents per MCF. The welfare loss associated with using a rate of return fee structure for transport pipelines is so small that it is hard to see how the additional complexity in regulation can be justified since the elasticity in the demand for gas is low. ${ }^{4}$

\footnotetext{
${ }^{4}$ Dahl (1994) show this empirically.
} 


\section{Timing of Investment in Pipeline Capacity}

Let us consider the case when gas is being transmitted a distance $\mathrm{L}$ over a pipeline of diameter D. Assume that the capital cost of this investment is $K_{0}$. The demand for gas is given by

$$
Q(t)=e^{\alpha t} Q_{0} D(p)
$$

where $\alpha$ is a random variable, and where $p$ will adjust to make demand equal supply.

The pressure limit is such that $\bar{Q}=e^{\bar{\alpha} T^{0}} Q_{0} D(\bar{p})$ (see figure 3).

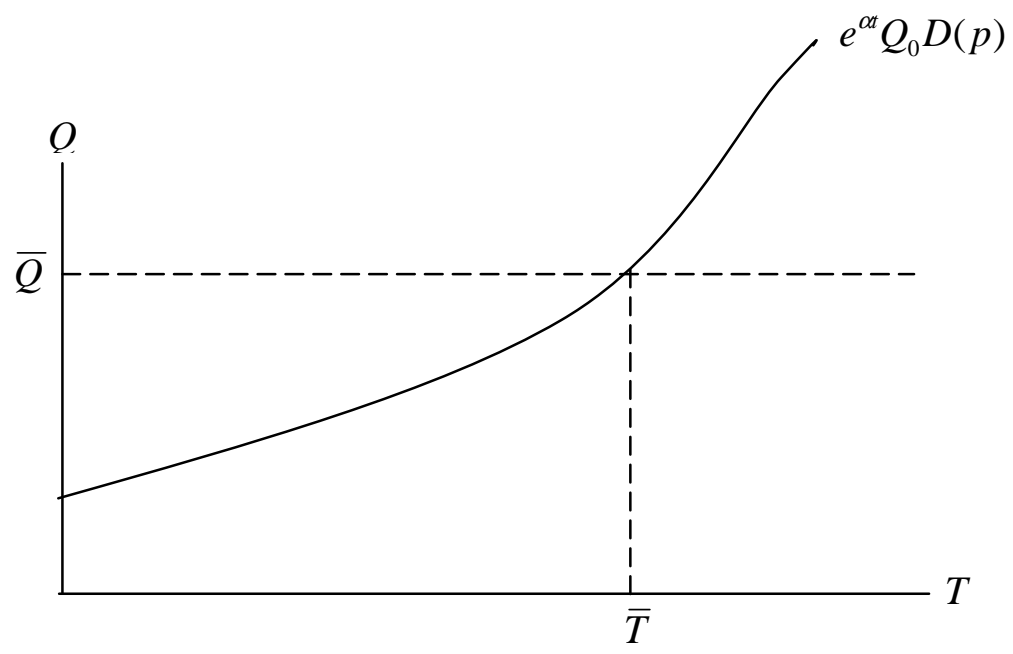

Figure 3

For simplicity we will assume that $\alpha>0$ is the only random variable and the mean, $\bar{\alpha}$, is known. Define $f(t)$ as the probability that at time $t, e^{\alpha t} Q_{0} D(p)=\bar{Q}$. If the constraint binds, the price of gas will have to increase, as gas cannot move to equilibrate 
the market (see Figure 4). The assumption that $\alpha>0$ means that if the pipeline becomes congested at some $t<T^{0}$, it will remained congested.

Now let us consider two possible stationary investment strategies such that pipeline capacity is doubled when the pipeline reaches a given fixed target. The policies are stationary in the sense that expected trajectory of throughput through the pipes repeats. Every time throughput reaches the target level, pipe capacity is doubled, and the cycle repeats. Given that investment occurs when capacity doubles, the time between investment is the doubling time, $T^{0}$. Note that all of the proposed investment strategies have the same timing after the first investment, and that they differ only in the timing of the first investment and the amount of throughput.

The first investment strategy we will consider is the strategy that would result from investing when the pipe is expected to reach full capacity. This policy is implemented by a sequence of investments, $\left\{2 K_{0}, \mathrm{~L}, 2^{n} K_{0}\right\}$, at $T_{i}^{0}=T_{i-1}^{0}+T^{0}, i=1 \mathrm{~L} N$. The present value of the cost of this investment sequence is

$$
V^{0}=e^{-r e T^{0}} \sum_{i=0}^{N} e^{-i r T^{0}} 2^{i+1} K_{0}+K_{0}=e^{-r e T^{0}} \bar{V}+K_{0}
$$

Note that the entire expenditure steam is discounted by $e^{-r e T^{0}}$ to reflect that the first expenditure occurs at $T^{0}$.

The second investment strategy we will consider is the strategy where the first investment occurs at at $T^{1}=\beta T^{0}$, and subsequent investments occur every time demand 
doubles, $T_{i}^{1}=T_{i-1}^{1}+T^{0}, i=2$, $\mathrm{L}, N$. The present value of the cost of this investment sequence is

$$
V^{1}=e^{-r r T^{1}} \sum_{i=0}^{N} e^{-i r T^{0}} 2^{i+1} K_{0}+K_{0}=e^{-r e T^{1}} \bar{V}+K_{0}
$$

Again, note that the entire expenditure steam is discounted by $e^{-r e T^{1}}$ to reflect that the first expenditure occurs at $T^{1}$. Except for the timing of the initial investment, the investment patterns of the two strategies are very similar. Investment occurs every time throughput doubles. Since the doubling time is the same, investment occurs at the same intervals.

Let us consider the revenue streams necessary to pay for the two investment strategies. First, consider the case where there will be a doubling of capacity when the system reaches full capacity. The first investment occurs at time $T^{0}$ and let $Q_{0}(t)$ be the flow of gas through the pipeline given this investment sequence. Let $c^{0}$ be the charge for transporting gas that will pay for this investment. Then

$$
P V^{0}=\int_{0}^{N T^{0}} c^{0} e^{-r t} Q_{0}(t) d t=c^{0} \int_{0}^{N T^{0}} e^{-r t} Q_{0}(t) d t
$$

Second consider the case where there will be a doubling of capacity when first investment occurs at time $T^{1}=\beta T^{0}$. Let $Q_{1}(t)$ be the flow of gas through the pipeline given this investment sequence. Let $c^{1}$ be the charge for transporting gas that will pay for this investment. Then 


$$
P V^{1}=\int_{0}^{N T^{1}} c^{1} e^{-r t} Q_{1}(t) d t=c^{1} \int_{0}^{N T^{1}} e^{-r t} Q_{1}(t) d t
$$

Since the first investment plan has less capacity and is thus more likely to have congested intervals, $Q_{1}(t) \geq Q_{0}(t)$ and $\int_{0}^{N T^{1}} e^{-r t} Q_{1}(t) d t \geq \int_{0}^{N T^{0}} e^{-r t} Q_{0}(t) d t=\bar{K}$.

If the revenue from the transport of natural gas is paying for the cost of the pipeline, then using equations (5) and (7) we get

$$
c^{0} \int_{0}^{N T^{0}} e^{-r t} Q_{0}(t) d t=e^{-r e T^{0}} \bar{V}+K_{0}
$$

Using equations (6) and (8) we get

$$
c^{1} \int_{0}^{N T^{1}} e^{-r t} Q_{1}(t) d t=e^{-r e T^{1}} \bar{V}+K_{0}
$$

Define $c^{2}$ such that

$$
c^{2} \int_{0}^{N T^{0}} e^{-r t} Q_{0}(t) d t=e^{-r e T^{1}} \bar{V}+K_{0}
$$

$Q_{1}(t) \geq Q_{0}(t)$ implies that $c^{2}>c^{1}$. Define $c^{3}$ and $c^{4}$ such that

$$
c^{3} \int_{0}^{N T^{0}} e^{-r t} Q_{0}(t) d t=e^{-r e T^{0}} \bar{V}
$$

and 


$$
c^{4} \int_{0}^{N T^{0}} e^{-r t} Q_{0}(t) d t=e^{-r T^{1}} \bar{V}
$$

Solving for $c_{0}, c_{1}, c_{2}, c_{3}, c_{4}$ we see that

$$
c^{4}-c^{3}=c^{2}-c^{0} \geq c^{1}-c^{0}
$$

and $c_{0}>c_{3}$. So

$$
c^{4}=\frac{e^{-r T^{1}}}{e^{-r T^{0}}} c^{3}
$$

and

$$
\begin{gathered}
c^{4}-c^{3}=\frac{e^{-r T^{1}}}{e^{-r T^{0}}} c^{3}-c^{3}=c^{3}\left(\frac{e^{-r T^{1}}}{e^{-r T^{0}}}-1\right) \\
\left(\frac{e^{-r T^{1}}}{e^{-r T^{0}}}-1\right) c^{0}>\left(\frac{e^{-r T^{1}}}{e^{-r T^{0}}}-1\right) c^{3}=c^{4}-c^{3} \geq c^{1}-c^{0} .
\end{gathered}
$$

The present value of the cost per thousand cubic feet of gas a day for one investment cycle for maintaining a $T^{0}-\beta T^{0}$ buffer of excess capacity has an upper bound given by

$$
\Delta C=\left(\frac{e^{-r T^{1}}}{e^{-r T^{0}}}-1\right) c^{0} \int_{0}^{T^{0}} e^{-r t} d t=\left(\frac{e^{-r T^{1}}}{e^{-r T^{0}}}-1\right) \frac{c^{0}}{r}\left(1-e^{-r T^{0}}\right)
$$

Let us calculate a simple example assuming that $r=0.10$ and a growth rate of 6.93 percent a year. This growth rate gives a doubling time of 10 years. Table 1 below 
gives the cost per MCF of maintaining excess capacity for tariffs of $\$ 0.10, \$ 0.25$ and $\$ 0.50$.

\begin{tabular}{|c|c|c|c|}
\hline \multicolumn{4}{|c|}{ Cost per MCF of Pipeline Buffer Capacity } \\
\hline & & Tariff per MCF & \\
\hline & 0.10 & 0.25 & 0.50 \\
\hline $\begin{array}{c}\text { Weeks of } \\
\text { Buffer Capacity }\end{array}$ & $\begin{array}{c}\text { Present Value of Cost } \\
\text { dollars }\end{array}$ & $\begin{array}{c}\text { Present Value of Cost } \\
\text { dollars }\end{array}$ & $\begin{array}{l}\text { Present Value of Cost } \\
\text { dollars }\end{array}$ \\
\hline 1 & 0.44 & 1.11 & 2.22 \\
\hline 2 & 0.89 & 2.22 & 4.45 \\
\hline 3 & 1.33 & 3.34 & 6.67 \\
\hline 4 & 1.78 & 4.45 & 8.91 \\
\hline 5 & 2.23 & 5.57 & 11.15 \\
\hline 6 & 2.68 & 6.69 & 13.39 \\
\hline 7 & 3.13 & 7.82 & 15.63 \\
\hline 8 & 3.58 & 8.94 & 17.89 \\
\hline 9 & 4.03 & 10.07 & 20.14 \\
\hline 10 & 4.48 & 11.20 & 22.40 \\
\hline 11 & 4.93 & 12.33 & 24.66 \\
\hline 12 & 5.39 & 13.47 & 26.93 \\
\hline 13 & 5.84 & 14.60 & 29.20 \\
\hline 14 & 6.30 & 15.74 & 31.48 \\
\hline 15 & 6.75 & 16.88 & 33.76 \\
\hline 16 & 7.21 & 18.02 & 36.05 \\
\hline 17 & 7.67 & 19.17 & 38.34 \\
\hline 18 & 8.13 & 20.32 & 40.63 \\
\hline 19 & 8.59 & 21.47 & 42.93 \\
\hline 20 & 9.05 & 22.62 & 45.23 \\
\hline 21 & 9.51 & 23.77 & 47.54 \\
\hline 22 & 9.97 & 24.93 & 49.85 \\
\hline 23 & 10.43 & 26.09 & 52.17 \\
\hline 24 & 10.90 & 27.25 & 54.49 \\
\hline 25 & 11.36 & 28.41 & 56.82 \\
\hline 26 & 11.83 & 29.57 & 59.15 \\
\hline
\end{tabular}

Table 1

\section{Cost of Congestion}

Let $p(t)$ be the price of gas in the absence of congestion, and $\bar{p}(t)$ be the price of gas if the pipeline is congested. Define 


$$
\Delta p(t)=\bar{p}(t)-p(t)
$$

as the rents in the price of gas a time $t$ due to congestion. The present value of the expected rents the consumer will pay over the planning period is:

$$
E[Z]=\int_{0}^{T^{0}} e^{-r t} \Delta p(t) d t
$$

As we have remarked, some of the stochastic elements that may lead to congestion are short term such as weather and others, such as the price of gas, are long term and reflect macroeconomic conditions. Forecasts on these elements either do not exist or they are subject to such errors that they are not very useful. To simplify the problem let us consider the case where congestion starts at some time $\hat{T}<T^{0}$, and demand grows at the rate $\bar{\alpha}$ in the interval $\left[\hat{T}, T^{0}\right]$. Let $\Delta \hat{p}(t)$ be the associated rents. This simplification is a lower bound to all other possible congestion paths, $\Delta \tilde{p}(t)$, that have the property that

$$
\int_{0}^{T^{0}} e^{-r t} \Delta \tilde{p}(t) \geq \int_{\hat{T}}^{T^{0}} e^{-r t} \Delta \hat{p} d t .
$$

The present value of congestion is given by

$$
V^{0}=e^{-r e T^{0}} \sum_{i=0}^{N} e^{-i r T^{0}} \int_{\hat{T}}^{T^{0}} e^{-r t} \Delta \hat{p} d t
$$


It is useful to compute an example. Assume that throughput grows at 6.93 percent a year. If initial throughput is $\frac{\bar{Q}}{2}$ (where the capacity of the pipeline is $\bar{Q}$ ) we can expect the pipeline to be congested in 10 years. Now suppose that congestion occurs at $\hat{T}<T^{0}$.

Table 2 below the expected cost transfers caused by congestion for one to twenty six weeks. The assumption made in calculating these transfers is that demand grows at the average rate after the capacity of the pipeline is reached. These transfers are initially very small, but grow exponentially.

\begin{tabular}{|c|c|c|c|}
\hline \multicolumn{4}{|c|}{ Cost per MCF of Pipeline Buffer Capacity } \\
\hline & \multicolumn{3}{|c|}{ Price per MCF } \\
\hline & 4.00 & 6.00 & 8.00 \\
\hline $\begin{array}{l}\text { Weeks of } \\
\text { congestion }\end{array}$ & $\begin{array}{c}\text { Present Value of Rents } \\
\text { dollars }\end{array}$ & $\begin{array}{c}\text { Present Value of Rents } \\
\text { dollars }\end{array}$ & $\begin{array}{c}\text { Present Value of Rents } \\
\text { dollars }\end{array}$ \\
\hline 1 & 0.11 & 0.17 & 0.23 \\
\hline 2 & 0.43 & 0.64 & 0.86 \\
\hline 3 & 0.95 & 1.42 & 1.90 \\
\hline 4 & 1.68 & 2.51 & 3.35 \\
\hline 5 & 2.61 & 3.92 & 5.22 \\
\hline 6 & 3.76 & 5.64 & 7.52 \\
\hline 7 & 5.12 & 7.68 & 10.25 \\
\hline 8 & 6.70 & 10.06 & 13.41 \\
\hline 9 & 8.50 & 12.76 & 17.01 \\
\hline 10 & 10.53 & 15.79 & 21.06 \\
\hline 11 & 12.78 & 19.17 & 25.56 \\
\hline 12 & 15.26 & 22.89 & 30.52 \\
\hline 13 & 17.97 & 26.96 & 35.94 \\
\hline 14 & 20.92 & 31.38 & 41.84 \\
\hline 15 & 24.10 & 36.16 & 48.21 \\
\hline 16 & 27.53 & 41.30 & 55.06 \\
\hline 17 & 31.20 & 46.80 & 62.40 \\
\hline 18 & 35.12 & 52.68 & 70.24 \\
\hline 19 & 39.29 & 58.93 & 78.58 \\
\hline 20 & 43.71 & 65.57 & 87.42 \\
\hline 21 & 48.39 & 72.59 & 96.78 \\
\hline 22 & 53.33 & 80.00 & 106.66 \\
\hline 23 & 58.54 & 87.80 & 117.07 \\
\hline 24 & 64.01 & 96.01 & 128.01 \\
\hline 25 & 69.75 & 104.62 & 139.50 \\
\hline 26 & 75.77 & 113.65 & 151.53 \\
\hline
\end{tabular}

Table 2 
Figure 3 below gives the expected cost of transfers due to congestion and the cost of buffer capacity for a price of gas of $\$ 6.00$ per MCF, and a tariff of $\$ .25$ per MCF. Not surprising at very small levels of congestion, it is not optimal to install buffer capacity even to prevent transfers. However, as can be seen in the table, after seven weeks consumers are willing to pay for more than seven weeks of buffer capacity and by sixteen weeks the transfers due to rents are more that twice the cost of buffer capacity. Note that a sixteen week error could be caused by an average growth rate of 7.1 percent as opposed to the 6.9 percent that results in throughput doubling every ten years

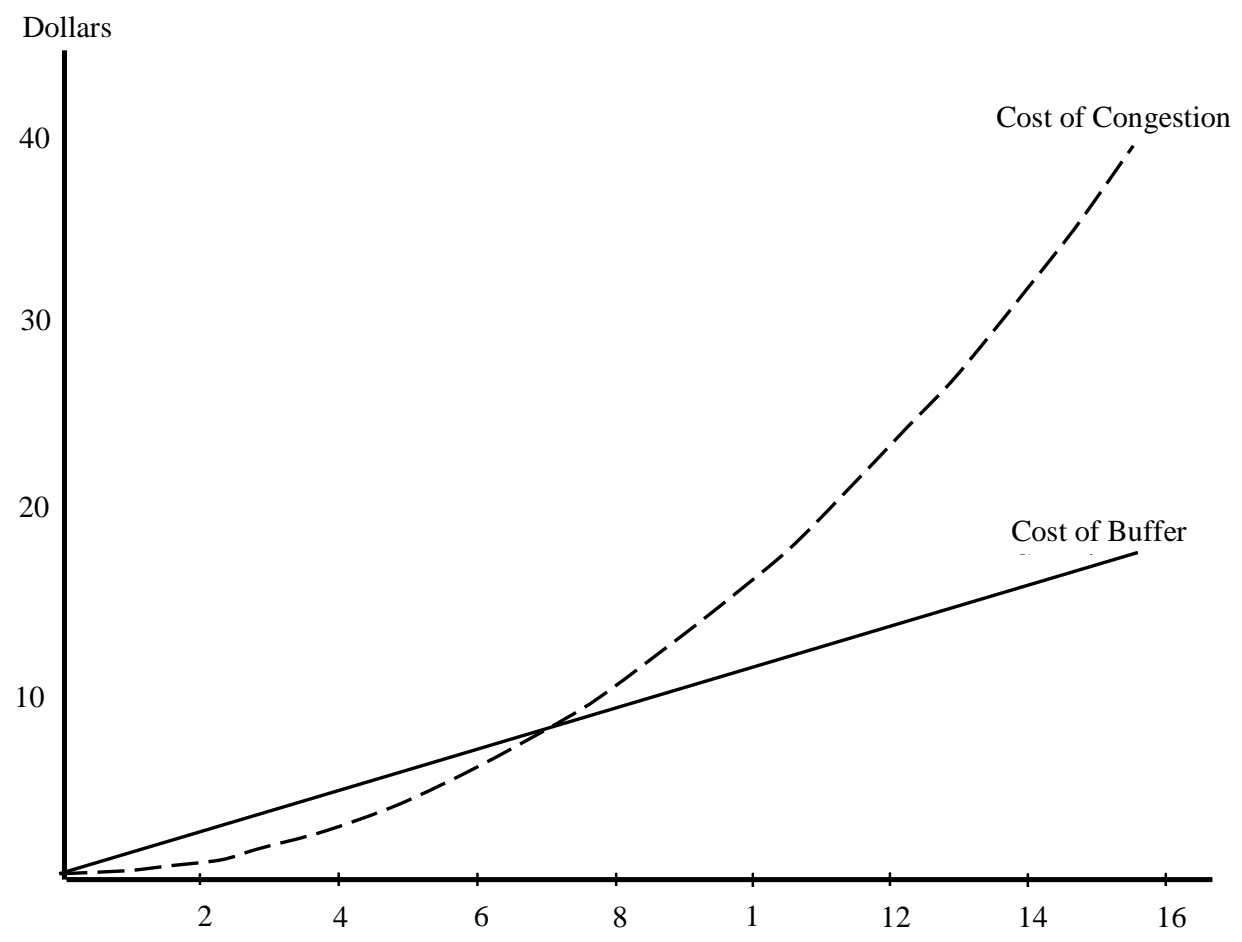

Figure 4 
The real world is very much more complicated and there are problems such as weather, macro-economic shocks, or war in the Middle East. The cost of buffer capacity is low and the cost of transfers that result from congestion to the consumers of gas of congestion is very high. The political economy of the situation is straight-forward. There are three interested parties: the operators of the pipeline, the sellers of gas and the consumers. If the operators of the pipeline have property rights, then they could collect or share the rents associated with transfers associated with congestion. If the market for access was competitive they would collect all the rents, otherwise they would share them. If the rate structure was regulated and access to the pipeline in the event of congestion is determined by queuing, the sellers of gas would prefer congestion. The expected value of congestion for the sellers of gas is positive.

\section{Conclusions}

The demand for gas is very inelastic and it is a two edged sword with respect to pipeline capacity in a regulated regime. An increase in demand that leads to congestion, results in a huge increase in the price of gas, and in substantial transfers if there are incomplete markets. However, inelastic demand also permits the implementation of a very simple rate structure. Further, the transfers are of such magnitude that consumers are willing to pay for substantial buffer capacity. Maintaining such buffer capacity is not Kaldor-Hicks superior as real resources are used to prevent transfers so compensation is not possible even in theory. However, if the objective of regulators is to protect the consumers, our calculations suggest that consumers would prefer to pay for excess capacity in the pipeline system rather than to risk the consequences of congestion. 


\section{References}

Bertoletti, P., and C. Poletti (1997), "Welfare Effects of Discriminatory Two-Part Tariffs Constrained by Price Caps", Economics Letters 56, pp. 292-298.

Brennan, T.J. (1989), "Regulating by Capping Prices", Journal of Regulatory Economics, No. 1, pp. 133-147.

Brito, D. L. and J. Rosellón, (2002a), "Pricing Natural Gas in Mexico: an Application of the Little-Mirrlees Rule," The Energy Journal, 23 (3), 81-93.

Brito, D. L. and J. Rosellón (2002b), Oportunidad de la Inversión en Gasoductos de GLP en México, El Trimestre Económico , México , Vol. LXIX (4), No. 276, pp. 567-581,

Brito, D. L. and J. Rosellón (2005a), "Price Regulation in a Vertically Integrated Natural Gas Industry: The Case of Mexico", The Review of Network Economics, vol. 4, issue 1, pp. 75-92, March.

Brito, D. L. and J. Rosellón (2005b), Strategic Behavior and the Pricing of Gas in Mexico, in Repsol YPF-Harvard Kennedy School Fellows 2003-2004 Research Papers, William Hogan, editor, pp. 115-126, Harvard University .

Brito, D. L., W. L. Littlejohn and J. Rosellón (2000), "Pricing Liquid Petroleum Gas in Mexico," Southern Economic Journal, 66 (3), 742-753.

Dahl, C. A. (1994), "A Survey of Energy Demand Elasticities for the Developing World," Journal of Energy and Development, Vol 18 (I), Autumn. pp. 1-48.

Dierker, E., Dierker, H., Grodal, B. (2001), ' 'Objectives of an Imperfectly Competitive Firm: A Surplus Approach.' in Economic Essays: A Festschrift for Werner Hildenbrand, edited by G. Debreu, W. Neuefeind, and W. Trockel. Berlin: Springer.

Fraser, R., (1995), "The Relationship Between the Costs and Prices of a Multi-Product Monopoly: The Role of Price-Cap Regulation," Journal of Regulatory Economics 8, pp.23-31.

Grande, O. S., and I. Wangensteen (2000), "Alternative Models for Congestion

Management and Pricing Impact on Network planning and Physical Operation," CIGRE, Paris, aug/sept.

Joskow, P. and J. Tirole (2002), "Transmission Investment: Alternative Institutional Frameworks," Mimeo.

Joskow, P. and J. Tirole (2005), Merchant Transmission Investment. The Journal of Industrial Economics, 53(2), 233-264.

Laffont, J.J., and J. Tirole (1996), "Creating Competition Through Interconnections: Theory and Practice," Journal of Regulatory Economics, 10: 227-256.

Law, P.J. (1995), Welfare Effects of Pricing in Anticipation of Laspeyres Price Cap Regulation-An Example, Mimeo, Department of Economics, University of Warwick, Coventry, Great Britain. 
Léautier, T.-O. (2000), "Regulation of an Electric Power Transmission Company," The Energy Journal, vol. 21, no. 4, pp. 61-92.

Loeb, M., and W. A. Magat (1979), “A Decentralized Method of Utility Regulation”, Journal of Law and Economics 22, pp. 399-404.

Neu, W. (1993), “Allocative Inefficiency Properties of Price-Cap Regulation," Journal of Regulatory Economics 5, pp.159-182.

Ramírez, J.C. and J. Rosellón (2002), "Pricing Natural Gas Distribution in Mexico", Energy Economics, Vol. 24, No. 3, pp. 231-248, May.

Rosellon, J. and J. Halpern (2001), "Regulatory Reform in Mexico's Natural Gas Industry: Liberalization in Context of Dominant Upstream Incumbent," Policy Research Working Paper 2537, The World Bank.

Sibley, D. (1989), “Asymmetric Information, Incentives and Price-Cap Regulation", RAND Journal of Economics 20, , pp. 392-404.

Vogelsang, I. (1989), “Two-Part Tariffs as Regulatory Constraints”, Journal of Public Economics 39, 1989, pp. 45-66.

Vogelsang, I. (2001), "Price Regulation for Independent Transmission Companies," Journal of Regulatory Economics, 20(2): 141-165, September. 